\section{A national primate centre?}

SrR - Your plan to keep the London Zoo going (Nature 358, 354; 1992) is misplaced; the British government and the zoo's potential customers have made it clear that they will not support the zoo. And, indeed, its closure in its present form would be no great tragedy. It cannot compete with wildlife parks, many within easy reach of London. It would be a tragedy if the Zoological Society became the steward of a disused wreck.

On the other hand, the premises at the zoo could be put to good use by turning them into a national primate centre. At present, research on primates is carried out in several different laboratories across the United Kingdom. The research is expensive and, because of the way these laboratories are dispersed, largely inefficient. At least in the centres I have visited, the conditions under which primates are kept are not ideal, and the costs of important new initiatives in primate research, such as neuroimaging, are prohibitive.

All that would change if such research were concentrated in one central national facility catering for all fields requiring primate research - studies of higher brain function, of neurodegenerative disorders and of AIDS are obvious examples. For example, the ideal facility for the study of higher brain function and neurodegenerative disorders would include positron and/or single photon emission tomography and a $1.5 \mathrm{~T}$ magnetic resonance imager, as well as high-grade neurophysiological equipment and first-rate computing facilities. No British university is likely to be able to establish such a facility, which is why a national primate centre, at what is now the London Zoo, is a compelling need.

After all, the site already has space, some facilities and the expertise of the Zoological Society and the staff to breed primates humanely. Indeed, the arrangement might dispense with the need to import primates. Funding for the centre would be provided by the Zoological Society with appropriate contributions from research councils and perhaps the pharmaceutical industry. The centre could provide excellent training facilities and even the most pessimistic calculation would show that the cost of concentrating Britain's primate research in one centre would be substantially less than the present cost of funding primate research at individual laboratories.

There would be many other advantages. The safety and well-being of the animals and staff could be more easily secured than at present. Indeed, the scale of the operation would probably justify a resident Home Office inspector, NATURE • VOL 358 • 27 AUGUST 1992

\section{Sheep count}

while the expertise of the Zoological Society and of the zoo staff could ensure that primate research carried out at the centre was absolutely necessary and justified and that conditions were as near as possible to the ideal.

A centre on this scale, run on the research hotel principle, could indeed be of immense scientific importance, bringing together as it would perhaps 200 or so scientists and support staff from different parts of Britain and elsewhere who would be working together on problems ranging across the whole field of biomedical science. And this development would at a stroke free the Zoological Society from its Victorian shackles and allow it a central role in contemporary biological and medical research.

\section{George Fink}

MRC Brain Metabolism Unit,

University Department of Pharmacology,

1 George Square,

Edinburgh EH8 9JZ, UK

SIR - Someone who, like Henry Gee (Nature 357, 639; 1992), seeks "to conserve the greatest amount of biodiversity in the smallest area" has missed the point of conservation. As Gee himself says, "convincing arguments stem from the concept of biodiversity as the sum of the interactions between species". Humankind is one of those species, part of nature, not set apart from it. Anything that diminishes nature diminishes humankind. To avoid that, we need to conserve the greatest amount of biodiversity in the largest area.

What is this life if, hooked on economic growth, there are no sheep and cows and other phenomena of nature to stand and stare at?

lan Davidson

Holly Wood House,

Broom Way, Oatlands Park,

Weybridge, Surrey KT13 9TG, UK

\section{AT\&T research}

SIR - The article on AT\&T Bell Laboratories' research (Nature 356, 184; 1992) suggesting that we are drastically cutting back on research misrepresents reality.

In 1980, the Bell Laboratories' budget for research and development was $\$ 1.25$ billion; in 1991, it was approximately $\$ 3.1$ billion. About 10 per cent of the total budget continues to be allocated to basic research.

Christopher Anderson also misunderstands my use of the ratio $60: 40$, which was a rough figure for the ratio of research in physical and materials sciences against software sciences. As vicepresident for research Arno Penzias has stated, we are planning to make this ratio closer to $45: 55$. The ratio, of course, has nothing to do with the proportion of our efforts devoted to basic research.

Anderson also quotes me as saying that we are abandoning basic research on superconducting materials in favour of the development of superconducting wires. In reality, we have reduced or eliminated our effort on wires and are concentrating on the basic properties of the materials.

On Anderson's more general point about the future of basic research at Bell Laboratories, I have no reason to believe that the laboratories will ever pull out of basic research.

C. K. N. Patel

AT\&T Bell Laboratories,

Room 1A-222, 600 Mountain Avenue,

Murray Hill, New Jersey 07974-0636, USA

\section{Catching AIDS}

SIR - Is it really 1992 ? The question posed by Lee Frank of the University of Miami School of Medicine (Nature 358, 10 ; 1992) is annoying at best and frightening to say the least: "I receive a relatively large number of reprints from areas of the world where AIDS is rampant. . . would like assurance. . . if one gets a paper-cut finger from the salivalicked envelope. . . needn't worry about the possibility of viable AIDS virus passage."

I am not a scientist, researcher or doctor but I am HIV positive and see myself as a "knowledgeable reader". It has been stated many times that the HIV virus is an extremely difficult virus to "catch"; that the amounts of virus found in saliva and other bodily fluids (other than blood, semen and vaginal fluids) are very small; and that the protein envelope is extremely fragile and cannot survive outside the body for any length of time. Given the number of infected people in the United States and the world, surely there would be very few individuals left uninfected if the virus were so easily transmitted. One needs to go only as far as the nearest library, local AIDS organization or physician for information. Or what about reading Time magazine? I think I can assure Mr Frank that he is safe. I would like to know if he has received any reprints concerning AIDS. If so, it is time to start reading them.

William Trusten

University of Southern California, Graduate Program in Molecular Biology, Los Angeles,

California 90089-1340, USA 